\section{Associations of Body Mass Index with Food Environments, Physical Activity and Smoking}

Gl_Forum 2019, Issue 2

Page: $10-23$

Full Paper

Corresponding Author: pablo.cb@live.com

DOI: 10.1553/giscience2019_02_s10

\author{
Pablo F. Cabrera-Barona ${ }^{1}$, Myriam Paredes' and Donald Cole 2 \\ 'Facultad Latinoamericana de Ciencias Sociales, Ecuador \\ 2University of Toronto, Canada
}

\begin{abstract}
This paper identifies spatial patterns of body mass index (BMI) and obesity in the Metropolitan District of Quito, Ecuador, by applying spatial autocorrelation. We identified BMI hotspots in eastern rural parishes, and hotspots of obesity in northern urban parishes. We then explored associations between distances to food outlets, physical activity and smoking (independent variables), and BMl and obesity (BMI > 30) (dependent variables) by applying global regressions (GR) and geographical weighted regressions (GWR). Smoking was found to be significantly negatively associated with BMl and obesity. Distance to supermarkets was found to be negatively associated with obesity.
\end{abstract}

\title{
Keywords:
}

BMI, obesity, smoking, physical activity, food outlets

\section{Introduction}

Malnutrition is a major health burden in developing countries (Müller \& Krawinkel, 2005). Increasingly, people in developing countries are influenced by obesogenic environments (Chopra \& Darnton-Hill, 2004). In lower- and medium-income countries, economic transitions may be associated with changes in human food-consumption, such as increasing consumption of processed foods (Poobalan \& Aucott, 2016). Additionally, the increasing consumption of fast foods is associated with weight gain (Niemeier et al., 2006). Ecuador is a medium-income developing country where obesity and being overweight are endemic. For instance, obesity and being overweight are practically three times more prevalent among children of school age compared with pre-school children, and excess weight and obesity combined affect $62.8 \%$ of adults (Freire et al., 2014).

The association between health outcomes, individual health-related variables and food environments is of great interest for public health interventions (Lytle \& Sokol, 2017). Body mass index (BMI) and obesity have been associated with objective and subjective context-level and individual-level variables (Alasmari et al., 2017; Fraser et al., 2012; Morland, Diez Roux, \& Wing, 2006). Obesity is defined as a BMI $>30 \mathrm{~kg} / \mathrm{m} 2$. Local food environments and diet have been comprehensively analysed using respondent-based perceived measures and 
geographical methods (Caspi et al., 2012; Lytle \& Sokol, 2017; McKinnon et al., 2009; Moore et al., 2008). Research about food environments has considered access to healthcare from multiple dimensions: availability, geographical accessibility, affordability, acceptability, and accommodation (Caspi et al., 2012; Penchansky \& Thomas, 1981).

Increasing accessibility to fast food outlets can increase consumption of fast food, which is associated with higher BMI (Fraser et al., 2012). In industrialized countries, adequate accessibility to and availability of supermarkets may improve diet among urban residents, as they can offer diverse healthy and affordable foods (Dubowitz et al., 2015). This is less the case in Latin America, where fresh and varied fruit and vegetables at affordable prices are traditionally obtained in open markets. Supermarket chains, although offering fresh produce, are also the main providers of ultra-processed foods, to the detriment of traditional ways of obtaining, cooking and consuming food (Freire et al., 2014; Monteiro et al., 2018). Although food environments are not the only influences on BMI, better access to high-quality foods can improve weight outcomes of urban residents (Gordon-Larsen, 2014). Environments offering opportunities for recreational physical activity can modulate the effects of the obesity drivers on a population's BMI (Swinburn et al., 2011), and regular physical activity can reduce the likelihood of excess weight (Swinburn et al., 2004).

Healthy habits such as doing physical activity contribute to quality of life, while the opposite happens with non-healthy habits such as tobacco consumption. The obesity epidemic has been compared to the tobacco epidemic. Smoking and obesity have a common link: both epidemics are related to the activities of global corporations that resist attempts made by public health organizations to change practices of tobacco and fast food consumption (Chopra \& DarntonHill, 2004; Courtney, 2006). Previous studies have related BMI and tobacco consumption as health determinants of populations, including urban residents (Aguilar-Salinas et al., 2001; Dare et al., 2015). Among school students, those aware of obesity were found to be more likely to be active smokers and regularly eat fast food (Alasmari et al., 2017).

Availability and geographical accessibility of food outlets are suitable for analysis using geospatial GIS approaches. 'Availability' refers to the number and types of food outlets from which a person can choose, while 'accessibility' reflects the geographical distance between the person and the food outlets: availability and accessibility may refer to the Euclidean distance between the person and the nearest outlet. Most of the research on food environments using GIS has measured distances to food outlets, and the density of these outlets (Charreire et al., 2010).

Methods supported by GIS have also considered socio-economic status and ethnicity variables as independent factors (Apparicio, Cloutier, \& Shearmur, 2007; Charreire et al., 2010; Moore et al., 2008; Zenk et al., 2005). Spatial autocorrelation analysis is a useful geographical technique to identify clusters. However, there is limited research applying spatial autocorrelation to food environments (Pineda \& Mindell, 2016). Additional geographical techniques such as geographically weighted regressions have been applied in an attempt to understand socialecological influences on body weight status (Chalkias et al., 2013; Chi et al., 2013; Fraser et al., 2012).

The literature referred to above indicates the existence of associations between weight and physical activity, weight and obesity, and weight and accessibility of food outlets. However, it 
is limited in the extent to which it studies weight as the effect variable of the covariates physical activity, smoking and access to food outlets through the application of multivariate regression models. Hence our work addressed two research questions. (1) In order to study spatial autocorrelations of the weight health outcomes, we asked 'Do hotspots of BMI/obesity exist in the study area?'. (2) In order to examine associations of weight health outcomes (BMI/obesity) with individual health-related variables (physical activity, smoking) and food environments (distances to food outlets), we asked 'To what extent is variation in BMI and obesity spatially associated with variation in physical activity, smoking and distances to food outlets?'. To answer these questions, we performed an explorative geospatial analysis of data from the Metropolitan District of Quito (MDQ), Ecuador.

\section{Methods}

The MDQ is and urban-rural administrative area that includes the city of Quito, the capital of the Republic of Ecuador. The city of Quito comprises 32 urban parishes. The Ecuadorean National Institute of Statistics and Census (2019) reports a population of 2.7 million people living in the MDQ.

For this study, three types of spatial analysis were used. The Getis Ord-Gi* index of spatial autocorrelation was applied to identify clusters of BMI/obesity. Global regressions and geographically weighted regressions were applied to identify potential associations of physical activity, smoking and distances to food outlets with BMI/obesity. The Moran's I measure of spatial autocorrelation was applied to assess the ability of the regression models to explain variation in $\mathrm{BMI} /$ obesity.

We used data obtained from a cross-sectional survey of a random sample population in the urban and rural areas of the MDQ, in the context of the Ekomer project. This project was funded by the International Development Research Centre of Canada (IDRC) and launched in 2016. The questionnaire comprised diverse questions relating to individual health and foodrelated behaviour (Paredes et al., in progress). Random survey sectors were generated, and in each sector interviewers visited randomly selected households, obtaining information from each head of household after informed consent was given. Each survey took between 20 and 45 minutes and was carried out between August and December 2017. We obtained 769 responses.

Supermarkets and organic markets are important determinants of the food environment, and access to these food outlets has been associated with health-related factors (Dubowitz et al., 2015; Jilcott Pitts et al., 2013). Within the context of the Ekomer project, we identified 77 supermarkets by searching the website of the Internal Revenue Service of Ecuador, as well as the websites of the main supermarket chains present in Quito. We also ran a survey of all agroecological markets (which include organic markets), identifying 24 in the study area. Figure 1 shows the locations of the supermarkets, agroecological markets and the individuals interviewed. 


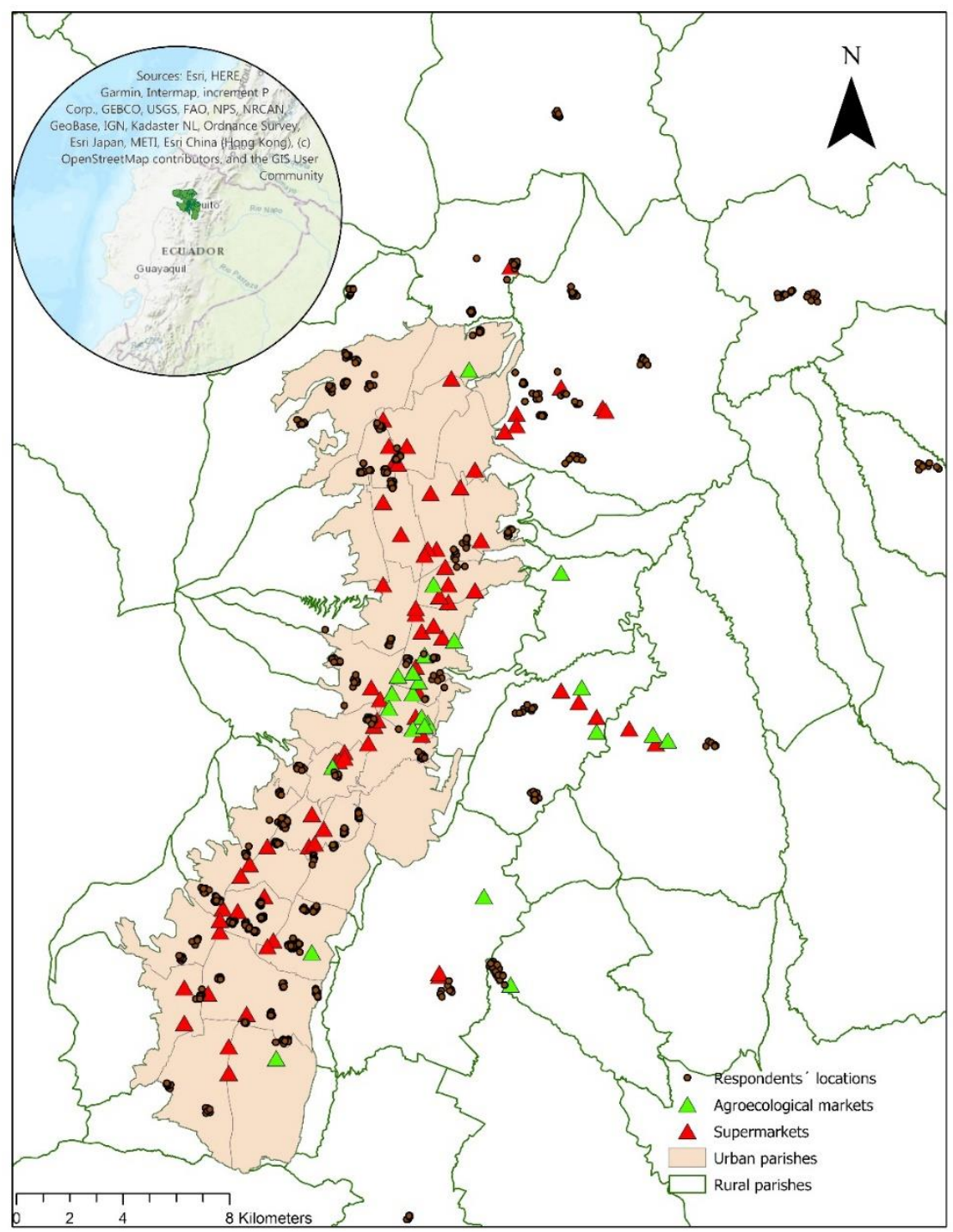

Figure 1: Study Area: The Metropolitan District of Quito. Interviews in rural parishes were taken in populated centres of the parishes.

Based on the conceptual framework presented in the Introduction, we chose the following variables from the questionnaire relaing to individual-level health: smoking and physical activity; direct anthropometric measures of weight and height, from which we calculated BMI. The smoking and physical activity variables were dichotomic, obtained by asking the following questions: 'Have you smoked in the last 30 days?' and 'Do you carry out activities that demand a slight increase of heart and respiratory rates for at least 10 minutes?'.

Additionally, the study considered a food environment-related measure: access to food outlets, which was obtained through GIS analysis. Respondents' locations and the locations of 
agroecological markets were geo-referenced in the field. Supermarket locations were obtained from websites. The Euclidean distances (in meters) from each respondent's location to the nearest supermarket and agroecological market were calculated. Euclidean distance has been demonstrated to be a useful proxy of real distances and travel times (Jones et al., 2010; Phibbs \& Luft, 1995).

The calculated distances were added to the dataset comprising the other variables. Data cleaning was conducted on the dataset: null responses for health variables were removed. After this filtering, 707 respondents were retained for regression analyses. To answer our first research question, 'Do hotspots of BMI/obesity exist in the study area?', an optimized cluster analysis was calculated for all BMI and obesity values (BMI > 30) by applying the Getis-Ord $\mathrm{Gi}^{*}$ statistic. This statistic facilitates the identification of clusters of high and low values for BMI and obesity. ArcGIS software was used to calculate Euclidean distances and the spatial autocorrelation indices.

To answer our second research question, 'To what extent is variation in BMI and obesity associated with variation in physical activity, smoking and distances to food outlets?', we calculated global regressions (GR) and geographically weighted regressions (GWR). We applied the regressions to assess the relationships between body weigh status (BMI/obesity the dependent variables) and tobacco consumption, physical activity, distance to supermarkets, and distance to agroecological markets (the independent variables). GWR4 software was used to perform the GR and GWR. GR is a multivariate linear regression based on the ordinary least squares method; GWR considers the spatial locations of all the variables and performs an explanatory analysis to identify possible non-stationarity of independent variables in relation to the dependent variable.

For regressions considering BMI as a dependent variable, 157 sets of data were considered, corresponding to the 157 respondents identified as obese (BMI > 30). An adaptive Gaussian kernel was used to calculate the GWR in order to mitigate the risk of there being no data within a kernel. To evaluate stationarity, we considered standard errors of the GR, and the quartiles of the local estimates of the GWR. There is non-stationarity if the interquartile range of the GWR's local estimates are more than double the standard errors of the GR estimates (Fraser et al., 2012). The Moran's I statistic was applied for the residuals of the GWRs, in order to identify inconsistencies in the regression model.

\section{Results}

We found that $22 \%$ of the interviewees were obese; $15 \%$ of respondents smoked, and the same percentage conducted vigorous activity for at least 10 minutes. The average distance to supermarkets was $1674 \pm 1994$ meters, while the average distance to agroecological markets was $3324 \pm 2541 \mathrm{~m}$.

Significant hotspots for high BMI were identified in the rural parishes located to the east of the city of Quito (Figure 2). 


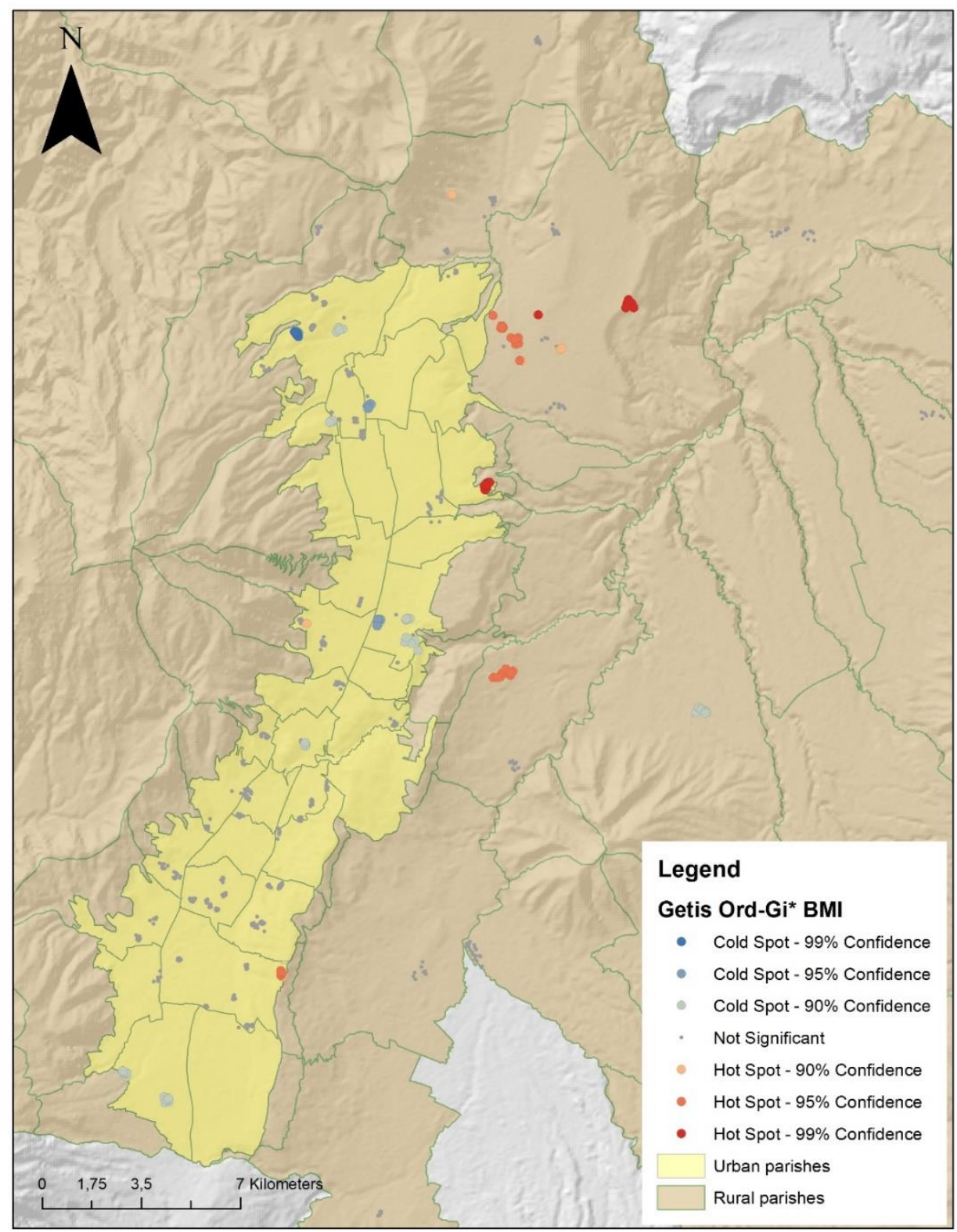

Figure 2: Getis Ord-Gi* for all the BMI values

Highly significant BMI coldspots were found in one northern urban parish, and other significant coldspots throughout some of the urban parishes. In the case of the Getis OrdGi*for BMI values $>30$, it is striking how clusters of very obese individuals are concentrated in the northern urban parishes (Figure 3). 


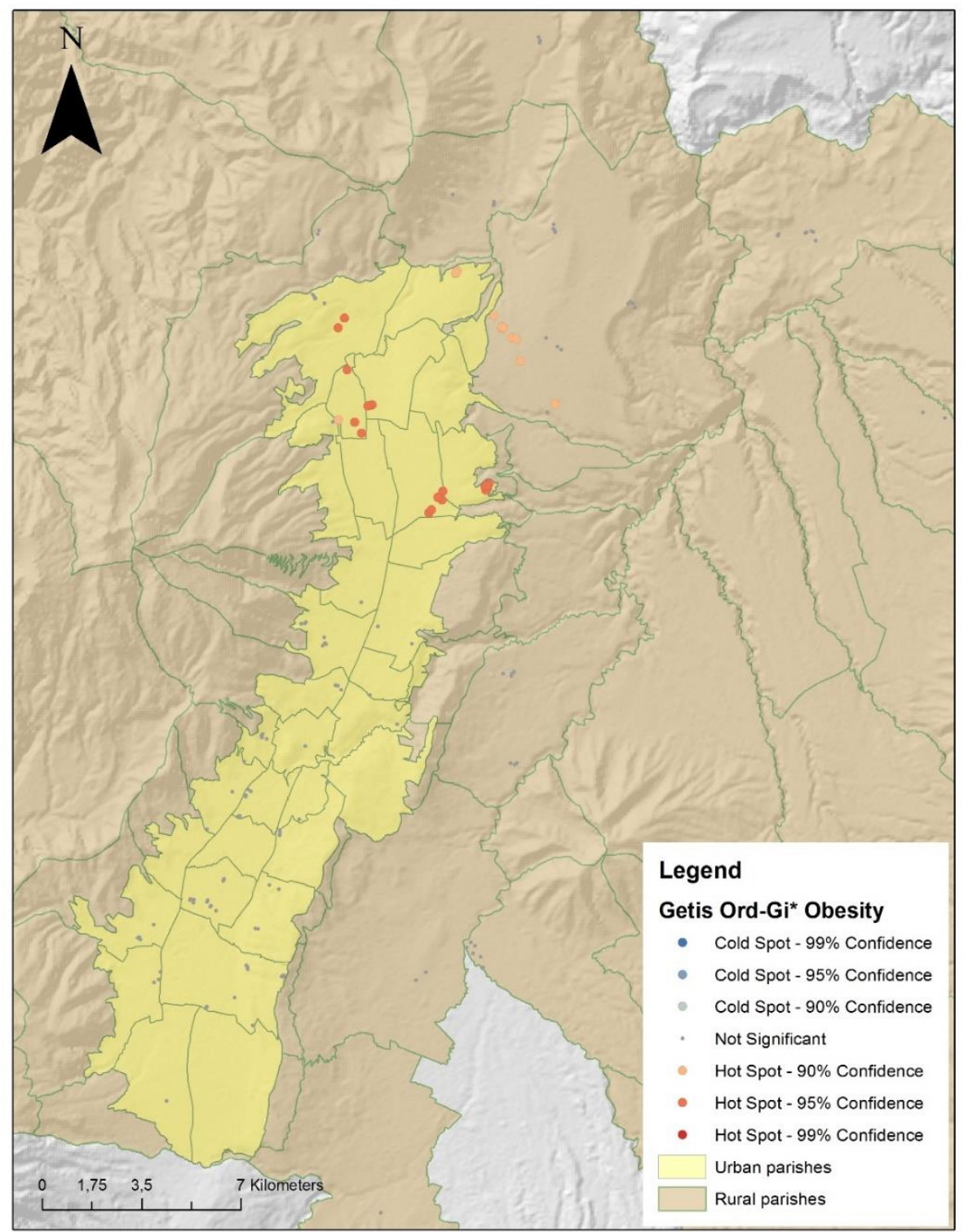

Figure 3: Getis Ord-Gi* for BMI values $>30$

When BMI (all values) was considered as a dependent variable (Table 1), smoking was found to be significant ( $99 \%$ confidence) with a negative coefficient, indicating that if people smoked they were less likely to have high BMI. Physical activity, distance to supermarkets and distance to agroecological markets were not found to be significant in the regression analysis. 
Table 1: Results of the GR for all BMI

\begin{tabular}{lll}
\hline & Estimate & p-value \\
\hline Intercept & 27.598 & 0.000 \\
Smoking & -1.309 & 0.005 \\
Physical activity & -0.232 & 0.495 \\
Distance to supermarkets & -0.000 & 0.585 \\
Distance to agroecological markets & -0.000 & 0.411 \\
& & \\
Adjusted R2 & 0.006 & \\
AICc* & 4104.085 & \\
\hline
\end{tabular}

*AICc: Akaike Information Criterion corrected

For the GR considering obesity (BMI > 30) as a dependent variable (Table 2), smoking was found to be significant. Distance to supermarkets was significant (significance level of 0.10) when considered in a one-tailed hypothesis, with greater distances to supermarkets being associated with lower obesity (Table 2). Distance to agroecological markets was not found to be significantly associated with obesity. Intercepts of the two GRs (the value of the dependent variable when all independent variables are equal to zero) were also found to be significant.

Table 2: Results of the GR for obesity $(\mathrm{BMI}>30)$

\begin{tabular}{lll}
\hline & Estimate & p-value \\
\hline Intercept & 33.796 & 0.000 \\
Smoking & -1.795 & 0.067 \\
Physical activity & 0.439 & 0.445 \\
Distance to supermarkets & -0.0003 & $0.064^{*}$ \\
Distance to agroecological markets & -0.0002 & 0.347 \\
& & \\
Adjusted R2 & 0.006 & \\
AICc & 850.394 & \\
\hline
\end{tabular}

*one-tailed hypothesis

If we look at the GWR for BMI as a dependent variable, an improvement of fit over the GR model can be seen: the Akaike Information Criterion corrected (AICc) is lower in the GWR model (Table 3). In the GWR models, no extreme variations of local estimates were obtained (low SD). However, evidence of non-stationarity was found for all the independent variables of the GWR with BMI as a dependent variable (Table 3) - that is, the relationships between each independent variable and the dependent variable differ among themselves and vary across the space. The results from the stationarity evaluation in the GWR model with the dependent variable 'obesity' show that the associations of obesity with smoking and with distances to markets vary across space. 
Table 3: Results of the GWR for all BMI

\begin{tabular}{llllll}
\hline & Min & Max & Mean & SD & Stationarity \\
\hline Intercept & 27.621 & 27.691 & 27.652 & 0.017 & Stationary \\
Smoking & -1.559 & -1.151 & -1.409 & 0.163 & Nonstationary \\
Physical activity & -0.293 & -0.188 & -0.249 & 0.041 & Nonstationary \\
Distance to supermarkets & -0.000 & 0.000 & -0.000 & 0.000 & Nonstationary \\
Distance to agroecological & 0.000 & 0.000 & 0.000 & 0.000 & Nonstationary \\
markets & & & & & \\
$\begin{array}{l}\text { Adjusted R2 } \\
\text { AICc }\end{array}$ & 0.007 & & & & \\
\hline
\end{tabular}

When the GWR considered obesity as a dependent variable, there was no improvement compared with the GR model (Table 4).

Table 4: Results of the GWR for obesity (BMI > 30)

\begin{tabular}{llllll}
\hline & Min & Max & Mean & SD & Stationarity \\
\hline Intercept & 32.717 & 33.891 & 33.796 & 0.068 & Stationary \\
Smoking & -1.938 & -1.758 & -1.862 & 0.061 & Nonstationary \\
Physical activity & 0.429 & 0.485 & 0.452 & 0.012 & Stationary \\
Distance to supermarkets & -0.0003 & -0.0003 & -0.0003 & 0.000 & Nonstationary \\
Distance to agroecological & 0.0001 & 0.0001 & 0.0002 & 0.000 & Nonstationary \\
markets & & & & & \\
$\begin{array}{l}\text { Adjusted R2 } \\
\text { AICc }\end{array}$ & 0.005 & & & & \\
\hline
\end{tabular}

Table 5 shows a random pattern for residuals of the GWR. This means that the regression models are well defined, and the independent variables used are useful for predicting BMI and obesity.

Table 5: Moran's I for residuals of the GWR

\begin{tabular}{lll}
\hline & BMI (all) & Obesity \\
\hline Moran's Index & 0.014 & 0.025 \\
z-Score & 0.286 & 0.417 \\
p-Value & 0.774 & 0.676 \\
\hline
\end{tabular}

\section{Discussion}

Our study identified spatial variations of BMI and obesity, and spatial variations between these dependent variables and the independent variables 'smoking' and 'distance to food outlets'. We also identified BMI hotspots in rural parishes. In general, urban areas tend to offer better spatial access to food stores than rural areas (Apparicio et al., 2007; Dai \& Wang, 2011). The urban parishes in the study area are in the city of Quito, where the majority of the supermarkets are concentrated. Most of the agroecological markets are located in central areas of the city.

Results of the Getis Ord-Gi* show that there are hotspots of obese people in the north of the city. In the center of this area, there is a concentration of supermarkets and agroecological markets, and some significant BMI coldspots (90-95\% confidence). The reason might be that 
this is where most universities are located, where people suffer no or very little socio-economic deprivation (Cabrera-Barona, Blaschke, \& Gaona, 2017; Cabrera-Barona et al., 2015). People here have greater access to education and financial resources, a situation that probably contributes to their decisions for a healthier diet. The first agroecological markets in Quito were found in this area as a result of people's interest in fresh produce and in purchasing direct from farmers. In these central urban parishes, accessibility to healthy food outlets is adequate, and a higher proportion of people are not overweight. However, further research in the study area is needed to explore relationships between weight, education and other socio-economic indicators.

Less affluent urban parishes, such as those located in the south of the study area, have poor availability of agroecological markets. Although supermarkets are present in these parishes, these are not the cheapest food outlets for fresh fruit and vegetables, and processed foods occupy greater areas than those dedicated to fresh food. As stated by Freire et al. (2014) and Monteiro et al. (2018), in Latin America supermarkets are the main providers of highly processed foods. Moreover, in the MDQ, supermarket corporations are able to locate cheaper stores in less affluent neighbourhoods. Food deserts are urban zones where cheap and nutritious food is unobtainable (Macintyre, 2007). To identify potential food deserts in less affluent parishes, future research should focus on the spatial distribution of greengrocers (fruterias) and markets, as well as the prices of these markets compared to those of supermarkets.

As Cummins \& Macintyre (2002) state, the term 'food desert' may be misleading, and a lack of clear information about this issue may cause flawed health policy. There is evidence that low-income households do not necessarily have poorer access to healthy food (Cummins \& Macintyre, 2002; Macintyre, 2007). Dubowitz et al. (2015) found that urban residents could do most of their food shopping outside their neighbourhood. However, we need to be careful of oversimplifications for our study area. In less affluent Ecuadorean neighbourhoods, there is generally at least one corner shop, but these shops do not necessarily sell healthy foods, and the food corporations often use them to advertise and promote processed foods. In our study area, populations of urban residents among whom obesity was less prevalent had to travel longer distances to get to a supermarket. These residents possibly also look for healthier sources of food such as markets and greengrocers. The latter have become very common in residential and business centers in Quito. However, further investigation is needed to establish any link between lower obesity levels and greater distances from supermarkets.

The results obtained from the GWR can be considered reliable thanks to the sample size and the Moran's I statistics, which suggest that the models are using relevant explanatory variables. These conditions minimize false-positives in the regressions (Fraser et al., 2012). Using BMI as the dependent variable, the GWR model represented an improvement over the GR model. The most striking results of the GWR and GR models was the inverse relationship between smoking and BMI and obesity, confirming the findings of Dare et al. (2015): smokers had a lower risk of obesity than non-smokers, while former smokers had the same risk of obesity as people who had never smoked. However, they also identified heavy smokers as more likely to be obese than people who had never smoked. Dare et al. concluded that steps to manage weight are needed when people are helped to quit smoking. Global food corporations control 
much of the food we eat, and to tackle obesity similar strategies are needed to those used against the tobacco industry (Chopra \& Darnton-Hill, 2004).

Physical activity was not found to be a significant factor in either GR. However, we also found that physical activity levels vary across space when BMI is used as a dependent variable, suggesting that in some areas of the MDQ people may be doing more exercise. In general, people with better access to green spaces are less likely to be overweight (Coombes, Jones, \& Hillsdon, 2010). The areas where average BMI is lowest are close to the city's biggest park: good access to this green space may be attracting local residents to exercise. Availability of green spaces is not always related to weight, but in neighbourhoods with better access to green areas, physical activity tends to be higher (Richardson, Pearce, Mitchell, \& Kingham, 2013). We therefore think that access to green spaces is a factor to be explored in future research in Ecuador.

Although Euclidean distance is useful to assess distances, spatial accessibility could be measured by other means, such as density analysis, travel-time modelling, or gravity-based accessibility (Cabrera-Barona et al., 2017; Charreire et al., 2010). Investigations addressing the problematics of the food environment and food deserts need to apply diverse geospatial methods, and we consider it important that future research should compare different approaches to evaluate spatial accessibility to food outlets.

We are agree with Turner et al. (2018) that food environment research should take into account differences between high income countries (HICs) and low and medium-income countries (LMICs). One of the biggest differences is the stability of prices and the types of food available in supermarkets in the HICs, as opposed to the LMICs where supermarkets are relatively new introductions. A related question is the importance of area-level socio-economic deprivation as an influence on BMI and obesity. For this, multilevel models can be applied that use a finergrained scale, for example measures of deprivation at census-tract level.

\section{Conclusion and Outlook}

Our investigation contributes to the public health and food environment literatures by employing spatial autocorrelation, and GR and GWR to uncover influences on BMI/obesity of individual-level health variables and context-level food environment variables. Further analyses should incorporate contextual and individual-level variables that can be associated with food environments, such as neighbourhood socio-economic status, and consumers' food preferences and behaviours.

This paper contributes to an understanding of weight factors and of spatial patterns of weight and obesity in a Latin American context. The study identified highly significant BMI hotspots in rural parishes, and significant obesity hotspots in northern urban parishes of the MDQ. Smoking was found to be inversely associated with BMI, whereas smoking and distance to supermarkets were found to be associated with obesity. We identified spatial variations in the relationships between the weight outcomes and most of the independent variables considered. The spatial heterogeneity of local associations of the health-related variables used suggests that weight may be influenced by additional local factors, which require further investigation. 
Including spatial methodologies at local scales can contribute to a better understanding of inequalities in health related to food environments, and to informing public health strategies that encourage people to move away from buying processed and more energy-dense foods in small stores and supermarkets, to purchasing fresher foods from markets and greengrocers.

Findings presented in this research are important for improving knowledge of the ecology of weight as a key health outcome. Finally, the research provides important insights for health policy and may support decision-makers in the Municipality of Quito to tackle the problematics of obesity in the MDQ.

\section{References}

Aguilar-Salinas, C. A., Vázquez-Chávez, C., Gamboa-Marrufo, R., García-Soto, N., de Jesús Ríos-González, J., Holgu1 $\square$ n, R., ... Mayagoitia, S. (2001). Obesity, Diabetes, Hypertension, and Tobacco Consumption in an Urban Adult Mexican Population. Archives of Medical Research, 32(5), 446-453. https://doi.org/10.1016/S01884409(01)00300-9

Alasmari, H. D., Al-Shehri, A. D., Aljuaid, T. A., Alzaidi, B. A., \& Alswat, K. A. (2017). Relationship Between Body Mass Index and Obesity Awareness in School Students. Journal of Clinical Medicine Research, 9(6), 520-524. https://doi.org/10.14740/jocmr2987w

Apparicio, P., Cloutier, M. S., \& Shearmur, R. (2007). The case of Montréal's missing food deserts: Evaluation of accessibility to food supermarkets. International Journal of Health Geographics, 6(4), 1-13. https://doi.org/10.1186/1476-072X-6-4

Cabrera-Barona, P., Blaschke, T., \& Gaona, G. (2017). Deprivation, Healthcare Accessibility and Satisfaction: Geographical Context and Scale Implications. Applied Spatial Analysis and Policy, 1-20. https://doi.org/10.1007/s12061-017-9221

Cabrera-Barona, P., Murphy, T., Kienberger, S., \& Blaschke, T. (2015). A multi-criteria spatial deprivation index to support health inequality analyses. International Journal of Health Geographics, 14(11). Retrieved from http:/ / www.pubmedcentral.nih.gov/articlerender.fcgi?artid=4376370\&tool=pmcentrez\&rendertype =abstract

Caspi, C. E., Sorensen, G., Subramanian, S. V., \& Kawachi, I. (2012). The local food environment and diet: A systematic review. Health \& Place, 18(5), 1172-1187. https://doi.org/10.1016/J.HEALTHPLACE.2012.05.006

Chalkias, C., Papadopoulos, A. G., Kalogeropoulos, K., Tambalis, K., Psarra, G., \& Sidossis, L. (2013). Geographical heterogeneity of the relationship between childhood obesity and socio-environmental status: Empirical evidence from Athens, Greece. Applied Geography, 37, 34-43. https://doi.org/https://doi.org/10.1016/j.apgeog.2012.10.007

Charreire, H., Casey, R., Salze, P., Simon, C., Chaix, B., Banos, A., ... Oppert, J.-M. (2010). Measuring the food environment using geographical information systems: a methodological review. Public Health Nutrition, 13(11), 1773-1785. https:/ /doi.org/DOI: 10.1017/S1368980010000753

Chi, S.-H., Grigsby-Toussaint, D. S., Bradford, N., \& Choi, J. (2013). Can Geographically Weighted Regression improve our contextual understanding of obesity in the US? Findings from the USDA Food Atlas. Applied Geography, 44, 134-142. https://doi.org/https://doi.org/10.1016/j.apgeog.2013.07.017

Chopra, M., \& Darnton-Hill, I. (2004). Tobacco and obesity epidemics: not so different after all? BMJ, 328(7455), 1558-1560. https://doi.org/10.1136/bmj.328.7455.1558

Coombes, E., Jones, A. P., \& Hillsdon, M. (2010). The relationship of physical activity and overweight to objectively measured green space accessibility and use. Social Science \& Medicine, 70(6), 816-822. https://doi.org/10.1016/J.SOCSCIMED.2009.11.020

Courtney, B. (2006). Is Obesity Reallythe Next Tobacco? Lessons Learned from Tobacco for Obesity Litigation. Annals of Health Law, 15(1), 61-106.

Cummins, S., \& Macintyre, S. (2002). 'Food deserts' - evidence and assumption in health policy making. BMJ, 325(7361), 436-438. Retrieved from https://www.ncbi.nlm.nih.gov/pubmed/12193363

Dai, D., \& Wang, F. (2011). Geographic Disparities in Accessibility to Food Stores in Southwest Mississippi. Environment and Planning B: Planning and Design, 38(4), 659-677. https://doi.org/10.1068/b36149 
Dare, S., Mackay, D. F., \& Pell, J. P. (2015). Relationship between Smoking and Obesity: A Cross-Sectional Study of 499,504 Middle-Aged Adults in the UK General Population. PLOS ONE, 10(4), e0123579-. Retrieved from https://doi.org/10.1371/journal.pone.0123579

Dubowitz, T., Zenk, S. N., Ghosh-Dastidar, B., Cohen, D. A., Beckman, R., Hunter, G., ... Collins, R. L. (2015). Healthy food access for urban food desert residents: examination of the food environment, food purchasing practices, diet and BMI. Public Health Nutrition, 18(12), 2220-2230. https://doi.org/DOI: $10.1017 /$ S1368980014002742

Fraser, L. K., Clarke, G. P., Cade, J. E., \& Edwards, K. L. (2012). Fast Food and Obesity: A Spatial Analysis in a Large United Kingdom Population of Children Aged 13-15. American Journal of Preventive Medicine, 42(5), e77e85. https://doi.org/https://doi.org/10.1016/j.amepre.2012.02.007

Freire, W. B., Ramirez-Luzuriaga, M. J., Belmont, P., Mendieta, M. J., Silva-Jaramillo, K. M., Romero, N., ... Monge, R. (2014). Resumen Ejecutivo. Tomo I: Encuesta Nacional de Saludy Nutricio $\square$ n de la poblacio $\square$ n ecuatoriana de cero a 59 an os. ENSANUT-ECU 2012. Quito.

Gordon-Larsen, P. (2014). Food Availability/Convenience and Obesity. Advances in Nutrition, 5(6), 809-817. Retrieved from http://dx.doi.org/10.3945/an.114.007070

Jilcott Pitts, S. B., Wu, Q., McGuirt, J. T., Crawford, T. W., Keyserling, T. C., \& Ammerman, A. S. (2013). Associations between access to farmers' markets and supermarkets, shopping patterns, fruit and vegetable consumption and health indicators among women of reproductive age in eastern North Carolina, U.S.A. Public Health Nutrition, 16(11), 1944-1952. https://doi.org/10.1017/S1368980013001389

Jones, S. G., Ashby, A. J., Momin, S. R., \& Naidoo, A. (2010). Spatial implications associated with using euclidean distance measurements and geographic centroid imputation in health care research. Health Services Research, 45(1), 316-327. https://doi.org/10.1111/j.1475-6773.2009.01044.x

Lytle, L. A., \& Sokol, R. L. (2017). Measures of the food environment: A systematic review of the field, $2007-2015$. Health \& Place, 44, 18-34. https://doi.org/10.1016/J.HEALTHPLACE.2016.12.007

Macintyre, S. (2007). Deprivation amplification revisited; or, is it always true that poorer places have poorer access to resources for healthy diets and physical activity? International Journal of Behavioral Nutrition and Physical Activity , 4(32), 1-7.

McKinnon, R. A., Reedy, J., Morrissette, M. A., Lytle, L. A., \& Yaroch, A. L. (2009). Measures of the Food Environment: A Compilation of the Literature, 1990-2007. American Journal of Preventive Medicine, 36(4), S124S133. https://doi.org/10.1016/J.AMEPRE.2009.01.012

Monteiro, C. A., Cannon, G., Moubarac, J.-C., Levy, R. B., Louzada, M. L. C., \& Jaime, P. C. (2018). The UN Decade of Nutrition, the NOVA food classification and the trouble with ultra-processing. Public Health Nutrition, 21(1), 5-17. https://doi.org/DOI: 10.1017/S1368980017000234

Moore, L. V, Diez Roux, A. V, \& Brines, S. (2008). Comparing Perception-Based and Geographic Information System (GIS)-based characterizations of the local food environment. Journal of Urban Health: Bulletin of the New York Academy of Medicine, 85(2), 206-216. https://doi.org/10.1007/s11524-008-9259-x

Morland, K., Diez Roux, A. V., \& Wing, S. (2006). Supermarkets, Other Food Stores, and Obesity: The Atherosclerosis Risk in Communities Study. American Journal of Preventive Medicine, 30(4), 333-339. https://doi.org/10.1016/J.AMEPRE.2005.11.003

Müller, O., \& Krawinkel, M. (2005). Malnutrition and health in developing countries. CMAJ: Canadian Medical Association Journal $=$ Journal de l'Association Medicale Canadienne, 173(3), 279-286. https://doi.org/10.1503/cmaj.050342

Niemeier, H. M., Raynor, H. A., Lloyd-Richardson, E. E., Rogers, M. L., \& Wing, R. R. (2006). Fast Food Consumption and Breakfast Skipping: Predictors of Weight Gain from Adolescence to Adulthood in a Nationally Representative Sample. Journal of Adolescent Health, 39(6), 842-849. https://doi.org/10.1016/j.jadohealth.2006.07.001

Paredes, M., Cole, D., Muñoz, F., April-Lalonde, G., Bert, P., Valero, Y., ... Ekomer project team. (n.d.). Assessing responsible food consumption in three Ecuadorian city-regions.

Penchansky, R., \& Thomas, J. W. (1981). The Concept of Access: Definition and Relationship to Consumer Satisfaction. Medical Care, 19(2), 127-140.

Phibbs, C. S., \& Luft, H. S. (1995). Correlation of travel time on roads versus straight line distance. Medical Care Research and Review, 52(4), 532-542.

Pineda, E., \& Mindell, J. (2016). Association of the food environment with obesity: a systematic review of geographical and statistical methods. The Lancet, 388, S89. https://doi.org/10.1016/S0140-6736(16)32325-X 
Poobalan, A., \& Aucott, L. (2016). Obesity Among Young Adults in Developing Countries: A Systematic Overview. Current Obesity Reports, 5(1), 2-13. https://doi.org/10.1007/s13679-016-0187-x

Richardson, E. A., Pearce, J., Mitchell, R., \& Kingham, S. (2013). Role of physical activity in the relationship between urban green space and health. Public Health. https://doi.org/10.1016/j.puhe.2013.01.004

Swinburn, B. A., Caterson, I., Seidell, J. C., \& James, W. P. T. (2004). Diet, nutrition and the prevention of excess weight gain and obesity. Public Health Nutrition, 7(1a), 123-146. https://doi.org/DOI: 10.1079/PHN2003585

Swinburn, B. A., Sacks, G., Hall, K. D., McPherson, K., Finegood, D. T., Moodie, M. L., \& Gortmaker, S. L. (2011). The global obesity pandemic: shaped by global drivers and local environments. The Lancet, 378, 804-814.

Turner, C., Aggarwal, A., Walls, H., Herforth, A., Drewnowski, A., Coates, J., ... Kadiyala, S. (2018). Concepts and critical perspectives for food environment research: A global framework with implications for action in lowand middle-income countries. Global Food Security, 18, 93-101. https://doi.org/10.1016/J.GFS.2018.08.003

Zenk, S. N., Schulz, A. J., Israel, B. A., James, S. A., Bao, S., \& Wilson, M. L. (2005). Neighborhood Racial Composition, Neighborhood Poverty, and the Spatial Accessibility of Supermarkets in Metropolitan Detroit. American Journal of Public Health, 95(4), 660-667. https://doi.org/10.2105/AJPH.2004.042150 